\title{
The Many Faces of Lifelong Learning: Recent Education Policy Trends in Europe \\ Draft for Journal of Education Policy
}

\author{
Andy Green
}

This article examines the rise of the discourse on lifelong learning across Europe and the variety of national policy trends which its rhetoric occludes. The ubiquitous presence of this meta-discourse in education and training policy-in-theory is seen as a singular event which can be ascribed to the impact of the variety of global forces on the education arena. It serves specific political functions in addition to signalling real changes in education and training systems. The duality of convergent rhetoric and divergent policy-in-practise is seen as a challenge to education policy analysis which requires multi-layered interpretation.

Education and training policy can increasingly be seen as a global commodity. Armies of international think tank experts and consultants analyse, develop, adapt and package policies to order for governments, corporations and other interested parties; international organizations - notably the OECD, the World Bank and the European Commission - evaluate national policies and seek to persuade national governments to adopt their favoured measures, with more or less potent forms of persuasion; and national education ministries keep a watchful eye on developments in other countries which they may adapt or borrow. Meanwhile, of course, countless independent academics in universities study policy developments and analyse their implications and effects. Where education policy was once a largely national affair, now - thanks to improved communications and cross-national data, and because of the global pressures of competition and transnational politics - it is now a fully internationalized, and at times internationally - traded, commodity.

This, by and large, is a good thing: it encourages cross-national collaboration in education and increases the evidence base from which policy can be developed. The narrow parochialism and occasional inertia of national policy-making in, say, the 1950s and 60s, has now given way to more dynamic and reflective process, although this may not necessarily be more democratically accountable to national electorates. For policy analysts this internationalization of policy makes life both more simple and more treacherous. On the one hand there is incomparably better data to work from, much of which cross-national; on the other hand, analysing policy becomes more complex because there is now a patina of international discourse overlaying national policy texts, which may not always run parallel with the implications of actual policies proposed. To put it simply, the internationalization of policy-making and analysis has generated an international educational rhetoric which can obscure as well as illuminate what is actually going on. To understand policy now we have both to decode the international rhetoric and analyse policy in context to appreciate dynamics of change. Visions and empirical trends are equally important and we understand little without analysing both, although too much of current policy analysis restricts itself exclusively to the discourse. 
This article seeks to draw out some of the dominant trends in current education policy in Europe and the developed world, highlighting where these are convergent and, alternatively, divergent, and commenting on some of the implications of different policy models. In brief compass, this will not attempt to do more than sketch out some of the major overarching trends, although it draws on and updates a more detailed analysis of policy developments reported elsewhere (Green, Wolf and Leney, 1999). However, it does seek to analyse both policy-as-discourse and policy-as-practise where possible, albeit here with illustration rather than reporting of systematic analysis, to avoid the pitfalls noted above. Following one of Marx's better methodological precepts about 'rising' from the abstract to the concrete (and hence, although not here, dialectically back to complex higher order theory), the analysis begins with the contexts and themes which drive and overarch international policy discourse before exploring in some more detail the complexities of policy in practise in some different states.

\section{The rhetorics and realities of lifelong learning and the knowledge society}

The dominant and organizing discourse in education and training policy at the turn of the millennium was lifelong learning (in the context the learning/knowledge society). This idea, whose origins lie way back and buried in the writings of forgotten educationalists some 70 years ago (eg Basil Yeaxlee, 1929), gained currency through the late 1980s and 1990s, not least through the advocacy of the OECD (1996) and the European Commission (1995), to become by the turn of the century almost ubiquitous in the developed world.

Although similar in some ways to earlier 1970s discourses around 'recurrent education', 'continuing education' and 'lifelong education' - the latter notably in the influential Learning To Be report by Edgar Faurè (UNESCO, 1972) - the 1990s idea of lifelong learning in a learning society decisively shifted the policy ground by stressing 'learning' rather than 'education', and 'society' rather than 'school'. The publication of Van der Zee's The Learning Society in 1991 and the European Commission's report Teaching and Learning: towards a Learning Society in 1996 provide two markers in continental Europe of the new society-wide emphasis. In the UK similar landmarks are visible with the publication of Stewart Ranson's book Towards the Learning Society in 1994 and the initiation in 1996 of the ESRC's Learning Society Research Programme.

Now almost every OECD country - from South Korea to Canada - makes reference to lifelong learning and the knowledge society in its education policies and the idea now constitutes something of a meta-discourse in policy terms. The notion is, of course, hopelessly vague, masking many different policy approaches, but it captures something real and significant in modern policy trends, and thus provides a convenient way into analysis.

As a meta-discourse, which is a relatively rare phenomena in the annals of education policy, lifelong learning has no doubt served various complex ideological purposes connoting, as it does, vision, change and, above all, 
policy inter-connectedness (or 'joined-up' thinking in UK policy parlance). However, at its heart is a very simple and significant notion. Lifelong learning implies that learning should take place at all stages of life cycle (from 'the cradle to the grave') and, in more recent versions (EC, 2001), that it should be 'life-wide' - that is embedded in all life contexts from the school to the workplace, the home and the community. The 'learning society,' therefore, is the vision of a society where there are recognized opportunities for learning for every person wherever they are and however old they should be. The notion is important because it is in fact new in education policy terms, signalling a radical shift from older education policy notions of the schooled society which have prevailed since the onset of mass education systems (Archer, 1979) and which focussed exclusively on formal learning. In the lifelong-learning- society rhetoric informal learning is as important as formal learning and the boundaries between the two are blurred.

Why has this discourse become so dominant and what are its implications? Three key contextual factors have acted as the drivers of lifelong learning policy and give the policy its contemporary salience. The first relates to demography and the ageing of populations which is common to all advanced countries. The second is global economic restructuring and the effects this has had on skills demands. And the third is cultural and social change and, in particular, the trend towards cultural pluralism and lifestyle diversity which has - to a greater or lesser extent - also impacted on all developed countries. Between them these three structural trends account for many of the recent policy changes in education and training and make some kind of lifelong learning policy virtually inevitable. The latter two are, of course, twin aspects of the same process of globalization.

\section{Demographic change}

All the advanced countries are now experiencing the affects of population ageing, albeit starting at different times and proceeding at different rates (Green, Wolf and Leney, 1999). The significance of this for education is immense. Firstly, it means that demand for educational provision gradually shifts through the age groups, with a permanent increase of retired people with specific educational needs. Secondly, it means that the average age of teachers is increasing which raises the costs of educational provision where teacher pay is linked to experience. Thirdly, and most important, it means that as workforces age, so there is an growing need for constant upgrading and updating of skills. These factors alone provides a powerful impetus for lifelong education and training (OECD, 1996). However, there is another effect which provides much of the hidden dynamic for policies adopted under lifelong learning. As populations age so the aged dependency ratio rises, increasing the costs of public services relative to number of people paying the taxes which fund them (OECD, 2000). This places immense pressures on public expenditure budgets thus raising constant demands for measures to increase efficiency and reduce costs in education as elsewhere.

\section{Globalization}

Globalization - including both economic restructuring and cultural change - is a controversial but undeniably significant process; for many sociologists the defining feature of our age (Castells, 1996). Although there has been some controversy about how far this process of accelerated internationalisation is peculiar to our age, 
rather than simply an extension of longstanding historical trends (Hirst and Thomson, 1996), there is little argument now that the process as we have experienced it since the 1970s is both qualitatively distinct - not least in the huge role of multinational corporations and foreign direct investment - and that it is here to stay, at least in some form. The pertinent questions now are not about whether it is novel, but about the nature of the contradictions embedded in this complex phenomenon (Hay and Marsh, 1999): what form will it take, what form should it take, and what are the benefits and costs of, say, free-for-all hyper- globalization on the liberal (US) model or some more regulated and contained process (as, for instance, in the espousal by Lionel Jospin in France of the controversial Tobin tax to calm financial markets). September $11^{\text {th }}$ has, of course, tragically demonstrated some of the malign consequences of unfettered globalization and its tendency to increase both global inequalities and cultural resistence to perceived American cultural and economic hegemony. Whether the 're-regulation' of global exchanges which this has engendered (so far vis-a-vis security, travel and criminal financial transactions) augurs a permanent shift remains to be seen, but there is no doubt that the phenomenon will continue to over-determine our world, including the world of education.

\section{Global economic restructuring}

At its core the concept of globalization denotes a secular rise in the frequency and speed of international exchanges of capital, labour, goods, services and ideas which literally transforms our notions of time and space (Harvey, 1989; Waters, 1995). A process of internationalization has indeed been underway for centuries with a spectacular rise in the latter half of the nineteenth century (Hobsbawm, 1994), but the current wave is exceptional. It has been driven by the triple forces of new communications technologies; the financial deregulation process that followed the collapse of the Bretton Woods system of fixed exchange rates in the early 1970s; and, not least, by the dramatic extension of multinational domination of world trade made possible by cheaper transport and communication and a liberal world order. This by no means brings forth the "borderless world' of the ahistorical fancies of the hyper-globalists, like Ken'ichi Ohmai (1990, 1996 ); in fact in the 1990s more new nation states were formed than in many previous decades and, as the Afghan conflict and subsequent 'war on terrorism' have shown, nation states are still major payers in the global scene. However, it does mean that in crucial areas of economic and social policy national governments have less autonomy than before in the face of the powerful multinationals and the demands of transnational organizations (Held; 1989; Green, 1997). It also means that far reaching changes are occurring in economic and social structures which have major impacts on education.

The economic process of globalization, which provides the major shaping force behind educational reform, involves major restructuring in all the countries which have been substantially drawn into the reach of the global market - ie most notably in Europe, North America and Asia. At the most profound level, globalization has intensified economic competition between regions and nations, by drawing more countries into the competition for markets for goods and services (Brown, Green and Lauder, 2001). Limited controls on capital movements have meant that foreign direct investment moves rapidly to the areas with most favourable conditions in terms of skills, labour costs, infrastructure and business environment. With massive improvements in the costs and efficiency of transport and communications, multinational enterprises can now easily dis-aggregate the different 
aspect of the production process, creating distributed networks of manufacturing and service units (Reich, 1991; Castells, 1996) in different countries where each is located in its most favourable environment. As a consequence, much of the manufacturing and assembly work has gone to countries with lower labour costs as has some of the more routine data processing the service industries (Martin and Schuman, 1997). The more advanced countries, which cannot hope to compete with the developing world on labour costs and still maintain living standards, are thus increasingly moving their production and service industries up into the higher value added areas of design, research, specialist production, and marketing. Hence the near universal call in the advanced nations, including the newly industrialised regions of east and south east Asia, for a shift towards the so-called knowledge-economy with its higher concentration of high skills and high value knowledge work (DTI, 1998; Leadbeater, 1999; Brown, Green and Lauder, 2001).

This shift towards the knowledge-based economy inevitably causes new demands for the higher order skills of professional and highly educated workers, so that in many countries the fastest growing occupations are in the professional, para-professional and higher technician categories (OECD, 2000). These new demands put pressures on education and training systems to raise the output of highly skilled people. Generally speaking these knowledge workers can be categorized into two groups according to leading US labour economist Robert Reich (2001). There are the 'geeks' who have high order specialist technical skills, whether these be in information technology or scientific research. And there are the 'shrinks' - those who dominate in business management and consultancy and whose stock in trade is in personal communications, public relations, persuasion, market analysis and so on. All such professional workers now deal for much of their working lives in symbolic languages and abstractions - ie what Reich calls 'symbolic analysis' (Reich, 1991). In addition to technical knowledge in their fields, they are required to have high order general competences in sorting and processing information and data, thinking conceptually and systemically, planning, personal communications and leadership. Education and training systems are required to produce more people who have these higher level skills and much current policy thinking is inevitably concerned with how to achieve this.

The changes do not stop with the professional knowledge workers, however. Globalization and intensified economic competition have forced a wave of economic restructuring which affects the skills demands on all workers. At the minimum, firms have been forced to increase efficiency through down-sizing, out-sourcing and flexible working practises, as well as to adapt their work organization to the new information technologies. Even for the lower skilled workers this means the need for new competences in computer skills as well attitudes and values that predispose them to being flexible. Above all, the new recruits to lower level jobs need good basic skills in IT, literacy and numeracy and the ability to learn and adopt. The lowest level jobs, which require few of these qualities and therefore little education, are in relative decline in most countries although in the US and the UK, many relatively low skilled jobs are still being created, particularly in the security and personal service occupations (Thurow, 1996). With decreased demand for their services those with the lowest levels of skills are therefore increasingly marginalised, either unable to find work or confined to low-paid and insecure jobs. Consequently, both governments and individuals are seeking more opportunities to raise their qualifications to levels (typically upper secondary graduation level at the least) that will enhance their employability and allow them to avoid the fate of the marginalized fifth of society in the most developed countries (Hutton, 1995). 
At the optimum, economic restructuring is leading to much more fundamental changes in work organizations and hence skills demands in enterprises. Firms wishing to compete at the high value-added end in manufacturing and services, where profits depend on skills and quality, are seeking to transform themselves into 'high- performance workplaces' though a variety of means (Keep and Mayhew, 1999). Manufacturing enterprises have sought to achieve high quality, efficient and flexible production through restructuring along socalled post-Fordist or 'lean production' lines (Streeck, 1996). Typically both strategies have involved adopting flatter hierarchies with 'single status' employment conditions, giving more responsibility for product and process innovation to the shopfloor worker, and requiring greater functional flexibility from all. Flexible specialisation in production has been achieved through the use of robots and multi-skilled workers (Piore and Sabel, 1994). 'Just-in-time' systems of stock and process control have been developed, after the Toyota model, to reduce wasteful stacking of inventories, and new 'quality control circles' have been introduced to reduce costly production defects. At the best, enterprises have introduced integrated manufacturing systems relying on high levels of automation, maximum flows of information, and the work of flexible teams of multi-skilled workers.

Enterprises such as these have become 'learning organizations' capable of continuous adaptation and change (Stahl et al, 1993). Employees frequently have to acquire multiple skills at different levels of complexity, as in vehicle manufacturing plants where production technicians move between functions as diverse as design, programming, maintenance, and operation. They also need more holistic understanding of their organizations and to work in teams where the totality of interacting skills and knowledge is more important than the individual part (Hamden-Turner and Trompenaars,1993). Learning organizations not only require everyone to be in a constant process of learning and adaptation, they also tend to see their prime function as engendering and sustaining the stock of organizational or 'collective' intelligence (Brown and Lauder, 2000).

Lifelong Learning policies aim respond to these global economic changes by, in the first place, seeking ways to increase general levels of learning and skills. They do this by promoting higher levels of participation in postcompulsory and higher education and also by encouraging greater take-up of adult learning and continuing training. The renewed emphasis on continuing training, and hence the stress on the lifelong nature of learning, is seen as essential for meeting the changing skills demands that arise out of rapid technological and organizational change in an era when workforces are also ageing (OECD, 1996, 2000). However, the lifelong learning/learning society vision goes further than merely promoting increases in formal learning and organized learning. It is also fundamentally about raising levels of non-formal and informal learning wherever this may take place (EC, 2001). This is seen as essential for two reasons.

Firstly, more informal learning is essential because expanding formal learning to the point where it will meet the new skills demands is simply too expensive to be borne by the state and individuals and employers have generally not been prepared to pay the costs of it. Secondly, informal learning can be vastly more flexible than formal learning which is often slow to respond to the fast changing nature of skills demands in the economy. When the state can no longer pay for the quantities of learning required, it invents the learning society so that 
the costs can be shared. Fortunately, new information technology, and particularly the different forms of ICTbased remote learning which they enable, make possible the development of myriad forms of informal and nonformal learning, whether this be in the workplace, the home or the community. The learning society is thus both the most affordable and most responsive way to meet the learning demands of the knowledge economy, as far as national governments are concerned. But it is also in tune with what many people want (OECD, 2000a).

\section{Cultural globalization}

Globalization has impacted not only economies but also on cultures and lifestyles. At a surface level national cultures appear to have become more homogeneous with the global penetration of anglo-phone western cultural practices. However, at a deeper level, cultures have become more diverse and lifestyles more varied, as some societies react against the forces of globalization and modernity and as global communications allow particular cultural forms to be reproduced and re-mixed (Robertson, 1995; Pieterse, 1995). Societies have also become more atomized and individualistic as a result of increasing social and geographical mobility, the weakening of the old social bonds of class, religion and region, and the decline of traditional family forms (Green, 1997; Reich, 1991). Consumer culture has also increased lifestyle diversity and social fragmentation. Cultural and lifestyle shifts in the heartlands of globalization have led to increasing diversity and pluralism and also to higher levels of uncertainty and risk (Beck; 1992, 2000; Giddens, 1994).

Youth transitions to adulthood and work have become both more protracted and more complex in recent years (Chisholm and Horrelmann, 1995). Reduced job opportunities for young people and continuing high levels of youth unemployment mean that young people are staying in school longer and gaining stable employment later. They are also marrying later and the average age of women at the birth of their first child is rising (CERI, 1996). Young people are tending to take increasingly varied and incremental routes into the adult world. Many make circuitous journeys through various education courses, part-time and temporary jobs, portfolio jobs, or special employment programmes. An increasing number find ways of combining part-time paid work with education and training, sometimes over long periods. A substantial proportion fall outside the institutional process of transition altogether and spend long periods without paid work or formal learning, although the majority perhaps still follow fairly traditional paths through formal post-compulsory education or training. Overall the diversity of situations and learning needs is increasing for young people.

The same may be said for adult work and family life patterns. The traditional (largely male) sequential pattern of education and initial training followed by steady career progression in a few long term employments has now been replaced for many by much more discontinuous, complex and unpredictable patterns of work, study and child-caring. In most developed countries there has been a trend towards shorter job tenure, more job hopping and forced redundancies, and a greater prevalence or part-time, temporary, and self-employed work (Hutton, 1997; OECD, 1996). More people are combining work and study, work and child-care, or multiple jobs in an increasingly complex fashion. Learning has ceased to be a front-loaded in the life-course, but is increasingly distributed through the life span depending on circumstances, and combined in ever more complex ways with other commitments. 
Patterns of family life and leisure have also changed markedly in the past 30 years in the developed countries. The decline of the traditional nuclear family and the multiplication new patterns of relationships and forms of family life are part of this, as is the huge rise in single occupancy households in Europe's capital cities. This and the explosion of identity politics and new cultural styles are part of a burgeoning lifestyle diversity that is a marked as the complex patterns of modern working life (Castells, 1997). These shifts create new bonds and allegiances at the same time as breaking down old patterns community and belonging. Class and geographical mobility have brought with them a secular decline in the bonds which historically tied neighbourhood communities, social classes and religious groups and, even, families. In one sense this means that societies are less divided. In another, however, and in the absence of new forms of cohesion, it represents a net loss of important sources of group solidarity, and therefore a more individualized society (Green, 1997). On measures of association, social trust, volunteering and political engagement, Social Capital in the USA has been in steep decline since the 1960s (Putnam, 2000), meaning that communities are becoming progressively weaker. Rising rates of crime and inter-community conflict suggest that social cohesion is also weakening in many European societies, where xenophobic parties of the far right increasingly seek to exploit the fissures and tensions engendered by globalisation's centrifugal forces (Green, 2001; Horsman and Marsall, 1994).

Lifelong learning policies are, in a sense, also responding to these changes in cultural life. They seek to provide a greater diversity of flexible learning opportunities, including different venues for and modes of learning, responding to the complexities of modern life and to the variety of individual preferences. Individualized learning careers involve individuals taking responsibility for constructing their own learning pathways and sustaining their own employability. They also mean institutions being responsive to their individual needs. The learning society is thus conceived as a society that provides learning opportunities for each in their own circumstances - horses for courses. In many cases, lifelong learning policy is also advocated as a way of promoting social cohesion in the teeth of growing individualism (EC, 2001), although it is often far from clear how this can be achieved where policies make little impact on unequal educational outcomes (Green and Preston, forthcoming 2002).

Lifelong learning policy in Europe thus has many common causes and objectives. However, in practise it takes many forms. One ideal-typical model, for instance, would envision the learning society as a grass-roots, demand-led efflorescence of new opportunities, networks and partnerships, facilitated by new technologies and driven by the market. In this model the individual takes primary responsibility for his or her own learning and governments limit their roles largely to advocacy and 'steering'. Organizations recognize their interest in developing learning environments, and invest in them to the degree that is commensurate with the benefits they receive from them. Another possible 'social partnership' model recognizes the importance of individual responsibility and also advocates multiple agency, diverse stakeholding and making the most use of new technologies. However, it differs from the first in placing greater stress on the limitations of the market and the importance of regulation. Analysis of policies in practise across European states shows the reality even more diverse than this (Green, Wolf and Leney, 1999). In practise, models of lifelong learning in Europe, for 
instance, range all the way from demand-led models of voluntary partnership in the UK (the network model) to the more formalized social partnership models of the northern continental and Nordic states, to the more statist models still prevalent in some of the southern states (such as Portugal and Greece) (Green, 2000a).

In what follows we explore these by focussing on three areas: regulation and governance; institutional structures; and curricula and assessment.

\section{Regulation and Governance}

Regulation and governance in education and training have been subject to almost continuous change in most advanced states during the past twenty years and have represented one of the most contested areas of policymaking. Regulation is common to all areas of education and training and has a major impact on all aspects of process and outcomes in education, so it is frequently seen as the key to understanding the way systems in general work. It is also a key marker of the salient differences between education systems (CEDEFOP, 2001).

The general trend in regulation and governance in European Union states - and indeed in the rest of the developed world - has been away from direct central government administrative control over educational processes and towards greater devolution of operational control to other levels of authority. Governments in many countries have begun to describe the role of the central ministries and agencies as 'steering by goals or objectives' rather than actual administration (Rinne, Kivirauma, Aro and Simola, 2001). Typically governments set the objectives and the targets, leaving lower level authorities and institutions more discretion in how they achieve these targets. Institutional performance may be measured against the goals set, and funding incentives may be attached to the performance against specified targets, but there is less prescription about how the targets should be met. Although target setting and evaluation may involve new forms of central control (as in the adoption of national curricula and standards in the UK), the net effect of these changes is generally seen to be one of decentralisation (Green, Wolf and Leney, 1999).

Various reasons are given for the shift towards decentralisation (OECD/CERI, 1995). It is often argued that decentralized decision-making is more effective because those making the decisions are closer to operational realities and more aware of local needs. It is also claimed to be more efficient because it forces institutions to be aware of the cost benefits of the decisions they make. Neo - liberal governments have tended to argue the case in terms of the efficiency of the market, whereas the European Commission generally couches it in terms of subsidiarity - the principle of devolving power to the lowest effective level - and there may be importance differences in the degree of marketization envisaged in each case, but the claim of greater efficiency is common to both. Modern education and training systems, like modern economies, are said to be now so complex that no government can effectively manage them from the centre. In any case devolving decision-making has the distinct advantage of enabling governments to avoid blame for unpopular decisions and things that go wrong (Lauglo, 1990).

The form that decentralization takes, however, has varied significantly from country to country (Green, Wolf 
and Leney, 1999). A number of countries have substantially devolved power in school education to geographical regions (Spain) or to language communities (Belgium). Power may be delegated to elected regional governments or to regional arms of the central ministries (deconcentration) or, as in the case of France, to both. In the latter case, it could be argued, one form of decentralisation is cancelled out by another (Corbett and Moon, 1996). The more typical pattern of change in the Nordic countries (and particularly in Finland, Norway and Sweden since this was already the case in Denmark), has been to devolve more responsibility down to the level of the municipality and local level, thus reducing the administrative functions of both central government and the regional authorities (Miron, 1996; Nilsson, 1996). Some countries (UK and Netherlands), on the other hand, have reduced the power of the middle public tiers and substantially delegated administrative and budgetary powers to the institutions themselves. This, at least in the case of the UK, is associated with the development of a quasi-market in education, whereby parents and students are given more choice of providers and institutions compete with each other for custom and funding (Gerwitz, Ball and Bowe, 1995; Le Grand, 1990). Although the direction of change in all cases has been the same - ie towards more devolution - substantial differences in fact exist between systems where the dominant decision-making powers are at the regional and local authority level and those where they largely rest with the institutions and markets. For instance, UK schools which have been given the power to hire and fire teachers and to spend the majority of the school budget are in fact in the position of small businesses operating in a controlled market. Schools in France and Germany, on the other hand, have been delegated some additional powers, but they are still allocated teachers by the public authorities, have discretion over only a small part of the total school budget, and tend not to regard themselves or operate as businesses (Corbett and Moon, 1996; Dascher, Rolff, and Stryck, 1995; Derouet, 1991; OECD, 1994). Full financial delegation and local management of schools, as in the UK case, cannot operate fully in continental systems where teachers are still civil servants employed and paid by the central or regional state authorities.

Vocational training may take place in a variety of dedicated institutions or at the workplace and can hardly be seen as a coherent system in the same way as education. Nevertheless, it is still substantially subject to regulation, particularly in relation to those parts which are publicly funded, and this has also been subject to change in many countries. For the most part these changes have involved new forms of public funding designed to enhance efficiency as where funding levels are more directly related to inputs and outputs (as in the 'taximeter system' in Denmark, and output- related funding in the UK and the Netherlands) (Green, Hodgson, Sakamoto and Spours, 2001). The implementation of performance-related funding may also be accompanied by tighter specification of goals and some de-regulation of control over processes. There has also been a tendency in a number of states towards new forms of standard-setting for vocational qualifications. This has sometimes involved giving the social partners enhanced roles in bodies which are authorized to set standards (as in the Netherlands). Vocational training provision is quite complex in most states and it rarely possible to determine different models of regulation which apply across the board in any given country. We may talk about a continuum of regulatory forms, from formalized systems of social partnership (as in Germany and Austria, where employer and employee organizations have major statutory roles in the apprenticeship) to informal voluntary partnership systems (as in the UK, where the union roles are limited and non-statutory), but these types can rarely be applied to all forms of training in a given country. There has, however, been a discernable 
trend towards devolving more power to the social partners in a number of countries, not least as a way of encouraging employer to invest more in training (CEDEFOP, 2001).

\section{Institutional Structures}

Structures of regulation and governance have changed markedly during the past two decades, but there has been less policy or actual change in relation to the structure of provider institutions themselves. The general tendency in compulsory school systems since the 1950s has been to move increasingly towards structures comprehensive school structures within European Member States, and this has continued with Greece, Italy, Spain and Portugal adopting non-selective systems during the past twenty years. The trend has also extended in some countries to the creation of integrated upper secondary schools as with the gymnasieskola in Sweden (the norm), the lycée polyvalent in France (occasional), tertiary colleges in the UK (not widespread and stalled) and most recently, the sogo gakko in Japan (small but growing) (Green, 2000). Against this there has been a marked trend in some countries such as the Sweden and the UK towards the diversification of types of secondary school within a comprehensive framework (OECD, 1994). These are generally specialist type schools that are allowed to select some children with particular talents in relation to the schools' specialist area, whether that may be sport or music.

Higher education has, on the whole, resisted moving towards a unitary system in most countries, and, in fact, the more common trend at present is for the addition of a new tier of vocational universities along the lines of the German Fachhoschulen, as in the creation of the AMKs in Finland and the vocational polytechnics in Austria (Birke, Blumberger and Tabering, 1996). Even where a unitary system has been created, as in the UK in the early 1980s, there are rapidly growing fissures between the elite research-led universities and the less well endowed former polytechnics (although some of these manage to propel particular departments into the top rank). Where there has been more institutional innovation is in relation to vocational training and special programmes for the unemployed. Here one can see many countries creating new types of providers or allowing the private sector to create these, especially in relation to special alternance schemes for the young unemployed (Grünewald, 1994).

Despite the widespread introduction of degrees of school choice in EU countries, and the concomitant emphasis on variety of school types that tends to go with this, there has not been a high level of innovation as regards institutional structures. Consequently the differences that have traditionally separated countries in this respect are still quite evident. The major fault-lines are, as ever, between those countries with selective school systems (Germany and other proximate countries, such as Austria, Belgium, the Netherlands and Switzerland) and the rest which are now predominantly comprehensive. The same regional differences are apparent in relation to the major types of initial vocational education and training. VET systems can generally be categorized into two types (OECD, 1985). There are those which are predominantly apprenticeship-based (Germany, Austria) and those which are predominantly school or college-based and where the apprenticeship is a largely residual phenomenon (most of the rest). The school-based model has become most common in recent years despite huge policy efforts in countries like France, the Netherlands and the UK to stem the secular decline of their 
apprentice systems due to the linkage of the latter with old and declining industries and because of the preference of students for more academic qualifications which allow more flexibility and status on the job market (CEDEFOP, 1995). Only Denmark (with the Basic Vocational Training or EFS - Erhvervs Faglige Grunduddannelser) and the Netherlands (with the ROCs) have managed to revive substantially their apprentice routes and this by creating hybrid or mixed-mode apprenticeships where training contracts can be based on the firm or the school (Drake and Germe, 1994).

What is interesting here is the regional basis of the differences between countries. It appears that selective secondary systems and dominant apprenticeship systems go together to some extent, and that they are supported by common contexts involving strong unions, effective social partnership and relatively high status for craft level jobs which are protected by labour market regulation (see Brown, Green and Lauder, 2001).

\section{Curriculum and Assessment}

Many of the policy changes that have occurred in curriculum and assessment across the EU Member States in recent years have shared a common orientation and relate to the contextual factors that have been identified above. At the compulsory school level, there has been frequently been an increased emphasis on foreign language learning, IT and what are often considered the key competences of numeracy, communications, teamworking and decision-making. Curriculum specialisation in many countries has been delayed to late in lower secondary education and indeed until the succeeding phase in some cases (EURYDICE, 1997). The emphasis has been increasingly on achieving a broad and balanced curriculum at all levels of school education. In the upper secondary phase, academic tracks have not seen spectacular changes in most countries, although there has been change in some countries as with the reforms of the Advanced level in the UK (with the creation of 'half' AS levels) and the general baccalauréat in France (with more clustering).

Major changes have been effected in the vocational tracks. In terms of content, the most common type of reform has been in the broadening of the vocational curriculum to reflect the demands of more fluid and demanding job roles. This has often involved rationalization and reduction of the number of the different vocational programmes (as with the apprentice programmes in Austria and Germany and the vocational lines in Sweden); the creation of dual certification systems as in the German Berufsakademien (Birke et al, 1998); and the creation of broad or generic vocational programmes (the GNVQ in England, BEP in France) which address the needs of occupational sectors rather than specific occupations, in part through the delivery of key skills and competences. This is often allied with an attempt to enhance the academic content of the vocational programme as has been the case in Sweden and with the BEP and vocational baccalauréat courses in France (Lasonen, 1997; Tanguy, 1991).

Changes in assessment and qualifications systems have extensive in many countries and the overall patterns are rather too complicated to discern many general trends, except to say that there has been a quite widespread move - following the development of NVQs in England and SVQs in Scotland - to assess competences as well as theoretical knowledge, particularly in the vocational areas. 
It would also be true to say in relation to the upper secondary phase that there has been considerable concern in many countries with the status disparities between general academic and vocational tracks and attempts have been made through qualification systems to achieve greater parity between these. These attempts may take the form of increasing the degree of commonality between curriculum and forms of assessment between the general and vocational tracks, as the French sought to do with the creation of a vocational baccalauréat alongside the general and technical baccalauréats in the 1970s and as has been done in Sweden with the enhancement of vocational lines to three year programmes like the general programmes (Lasonen, 1997). A weaker alternative to this form of integration has been the development of curriculum frameworks as in the UK which maintain unaltered the distinctiveness of the different tracks, both in terms of curriculum and assessment, but place them within a common framework with other tracks with which they are accorded parity of esteem (although this may turn out to be nominal than real).

Higher education and continuing training have also seen widespread change in curricula and assessment. In the case of higher education this has mainly taken the form of internationalising curricula (OECD, 1996b) and paying more attention to IT and key skills, with less change to systems of assessment and qualification (although with the notable exception of Germany introducing a bachelors degree alongside its traditional Magister qualification). In continuing training the emphasis in many countries, as with initial VET, has been on the acquisition and assessment of key skills and competences. The major changes in assessment and qualifications have involved, apart from the rationalization of certificates mentioned earlier, more assessment of competences and the development of various means for accrediting prior learning and experience, such as the NVQs in England and the bilans de competence in France (CEDEFOP, 2001). Creating greater transparency and portability in through skills recognition has become a key part of the European Commission agenda for lifelong learning (EC, 2001).

Whilst these trends are to a degree common across many countries, they hardly mask the considerable diversity in curricula and assessment systems that obtain across the EU Member states (EURYDICE, 1997). At the most general level this relates to the degree of specialisation of curricula and the level of integration within qualification systems. In each case one may posit a continuum with specialised/fragmented systems at one end and universlized/integrated systems at the other. In the case of curricula, one might put the UK and Germany near to the specialist end and Denmark and Sweden (and possibly France) close to the universalistic end (McLean 1990). In terms of assessment and qualification systems, the UK and Germany would be still considered as rather fragmented, and France and some of the Nordic countries relatively integrated.

\section{Converging divergences around regional models}

The common context of global change has generated some powerful centrepetal forces for educational change in Europe. New technology, economic restructuring and demographic and cultural shifts have undoubtedly had a common effect in aligning European education systems increasingly in the direction of choice, diversification, flexibility and decentralization. To this extent the international rhetoric of lifelong learning, which endlessly re- 
cycles these motifs, signifies a real directional convergence in policy principles. However, policy-in-practise still varies markedly across European states and lifelong learning has many faces depending on where it is encountered. In many respects this represents an increasing convergence around regional models that remain quite distinctive.

Mediterranean states (including France) remain relatively centralised, statist and comprehensive with a continuing domination of a fairly traditional educational paradigm. German-speaking states have tended to be more regionalised with strong social partnership models of governance and regulation, but are generally more prone to academic selection and curricula specialisation than their Mediterranean counterparts. The UK and the Netherlands have moved furthest towards a quasi-market model, with high levels of institutional diversification and autonomy and, in the UK case, and continuing preference for curricula specialisation. The Nordic states have moved partially and cautiously in this direction too, but they still stand apart in their regional affinities for local public control combined with structural and curricula integration and universalism. The Nordic systems are still amongst the most comprehensive in their institutional structures and egalitarian in selection and admissions policies anywhere. They are also relatively unique in their tendency to combine primary and lower secondary education in a single institution. The Nordic states also tend to have exceptionally wide participation in adult continuing education and training (OECD, 2000) and have, arguably, gone further than most in realizing the goals of lifelong learning. These structural differences still seem to matter. It is no coincidence that of all the country populations surveyed the International Adult Literacy Survey the three with the flattest distributions of literacy skills amongst their adult populations were all Nordic states (OECD, 12000; Green and Preston forthcoming, 2001).

Governments tend to measure national progress towards the goals of the 'learning society' in terms of rises in average levels of participation, skills and qualification. Perhaps it is time now to start looking rather at how these are distributed. To live up to its ideal the learning society must be about both increasing and widening access to knowledge and skills.

\section{References}

ARCHER, M. (1979) The Social Origins of Education Systems (London: Sage).

BECK, U. (1992) Risk Society: towards a New Modernity (London: Sage).

BECK, U. (2000) What is Globalization? (Cambridge: Polity Press).

BIRKE, B., BLUMBERGER, A. and TABERIG, A. (1996) 'Post-16 Strategies and the Austrian Reforms' in J. Lasonen (ed) Reforming Upper Secondary Education in Europe: The Leonardo da Vinci Project on Post-16 Strategies (Jyväaskyä: University of Jyväaskyä).

BROWN, P., GREEN, A. and LAUDER, H. (2001) High Skills: Globalization, Competitiveness and Skill 
Formation (Oxford: Oxford University Press).

BROWN , P. and LAUDER, H. (2000) 'Human Capital, Social Capital and Collective Intelligence' in S. Baron, J. Schuller, and J. Field (eds) Social Capital: Critical Perspectives, Oxford University Press.

CASTELlS, M. (1996) The Information Age: Economy, Society and Culture, Volume 1 - The Rise of the Network Society (Oxford: Blackwell).

CASTELlS, M. (1997) The Information Age: Economy, Society and Culture, Volume 2 - The Power of Identity: (Oxford: Blackwell).

CEDEFOP (2001) Training and Learning for Competence: Second Report on Vocational Training Research in Europe (Luxemburg: Office for Publication of the European Communities).

CEDEFOP (1995) Apprenticeship in the EU Member States ((Thessaloniki: CEDEFOP).

CERI (1995) Decision-Making in 14 OECD Education Systems (Paris: OECD).

CHISHOLM, L. and HORRELMAN, K (1995) 'Adolescence in Modern Europe. Pluralized Transition Patterns and their Implications for Personal and Social Risks', Journal of Adolescence, 18, pp. 129 - 158.

CORBETT, A. and MOON, B. (eds) (1996) Education in France: Continuity and Change in the Mitterand Years, 1982-1995 (London: Routledge).

DASCHER, P., ROLFF, H.-G. and STRYCK, T. (1995) Schulautonomy - Chancen und Grenzen (Weinheim: Juventa).

DEPARTMENT OF TRADE AND INDUSTRY (DTI) (1998) White Paper: Our Competitive Future: Building the Knowledeg-Driven Economy (London:DTI).

DEROUET, J. L. (1991) 'Lower Secondary Education in France: form Uniformity to Institutional Autonomy', European Journal of Education, 26 (2) pp. 119-132.

DRAKE, K. and GERME, J.-F. (1994) Financing Continuing Training: What are the Lessons from International Comparison? Synthesis report (Berlin: CEDEFOP).

EUROPEAN COMMISSION (1995) White Paper: Teaching and Learning - Towards the Learning Society (Brussels: European Commission).

EUROPEAN COMMISSION (2001), A Memorandum on Lifelong Learning, (Brussels: European 
Commission).

EURYDICE (1997) Dix Années de Reforme de l'Ecole Obligatoire (Brussels: European Commission).

GERWITZ, S. BALL, S., and BOWE, R. (1995) Markets, Choice and Equity (Buckingham: Open University Press).

GIDDENS, A. (1994) Beyond Left and Right: The Future of Radical Politics (Cambridge: Polity Press).

GREEN, A. (1997) Education, Globalization and the Nation State (Basingstoke: Macmillan).

GREEN, A. (2000) 'Converging Paths or Ships Passing in the Night? An English Critique Japanese School Reform,' Journal of Comparative Education, 36 (4), pp.

GREEN, A. (2000a) 'Lifelong Learning and the Learning Society: Different European Models of Organization' in A. Hodgson (ed) Politicies, Politics and the Future of Lifelong Learning (London: Kogan Page).

GREEN, A. (2001) Education, Globalisation and the Nation State: the Changing Role of the National Education and Training Systems (London: NACETT).

GREEN, A. and PRESTON, J. (forthcoming 2002) 'Education and Social Cohesion: Re-Centering the Debate', Peabody Journal of Education and Development (forthcoming, 2002).

GREEN, A., WOLF, A. and LENEY, T (1999) Convergence and Divergence in European Education and Training Systems (London: Institute of Education).

GREEN, A., HODGSON, A., SAKAMOTO, A. and SPOURS, K. (2000) 'Financing Vocational Education and Training' in P. Descy and M.Tessaring, M. (eds) Training in Europe. Second Report on Vocational Training Research in Europe 2000: Volume 1, Cedefop Reference series (Luxembourg: Office for Official Publications of the European Communities).

GRÜNEWALD, U. (1994) (ed) The Structural Meaning of Alternance in the Context of the Initial Education and Vocational Training Systems (Berlin: PETRA/BIBB).

HAMPDEN-TURNER, C. and TROMPENAARS, F. (1993) The Seven Cultures of Capitalism (London: Piatkus).

HARVEY, D. (1990) The Condition of Post-Modernity (Oxford: Blackwell). 
HAY, C. and MARSH, (1999) (ed) De-mystifying Globalization (New York: St Martins Press).

HELD, D. (1989) Political Theory and the Modern State (Cambridge: Polity).

HIRST, P. and THOMPSON, G. (1996) Globalization in Question: The International Economy and Possibilities of Governance (Cambridge: Polity Press).

HOBSBAwM, E. (1994) The Age of Extremes: The Short Twentieth Century, 1914-1991, (London: Michael Joseph).

HORSMAN, M. and MARShALL, A (1994) After the Nation-State: Citizens, Tribalism and the New World Order (London: Harper Collins).

HUTTON, W. (1995) The State We're In (Chatham: Mackays).

HUTTON, W. (1997) The State To Come (London: Vintage).

KEEP, W. and MAYHEW, K. (1999) 'UK's VET Policy and the 'Third Way': Following a High Skills Trajectory or Running up a Dead End Street? Journal of Education and Work, 12 (3) pp. 3232-46. ESRC Seminar Paper, December (University of Warwick).

LAUGLO, J. (1990) Factors behind Decentralization in Education Systems: a Comparative Perspective with Special Reference to Norway', Compare, 20 (1), pp. 21-39.

LAUGLO, J. (1995) 'Forms of Decentralization and the Implications for Education', Comparative Education, $31(1)$.

LEADBEATER, C. (1999) Living on Thin Air (Harmondsworth: Penguin).

LE GRAND, J. (1990) Quasi-Markets and Social Policy: Studies in Decentralization and Quasi-Markets 1 (Bristol: SAUS Publications).

MARTIN, H. P. and SCHUMANN, H. (1997) The Global Trap: Globalization and the Assault on Democracy and Prosperity (New York : Zed Books).

McLEAN, M. (1990) Britain and the Single Market Europe (London: Kogan Page).

MIRON, G. (1996) 'Choice and the Quasi-Market in Swedish Education', Oxford Studies in Comparative Education 6 (1). 
NILSSON, I. (1996) ‘Public and Private Schools in Sweden’, Paper to ECER Conference, Seville.

OECD (1985) Education and Training Beyond Basic Schooling (Paris: OECD).

OECD (1994) School : A matter of Choice (Paris: OECD).

OECD (1996) Lifelong Learning for All (Paris: OECD).

OECD (1996b) Internationalisation of Higher Education (Paris: OECD).

OECD/Statistics Canada (2000) Literacy in the Information Age: Final Report of the International Adult Literacy Survey (Paris:OECD).

OECD (2000a), Where are the Resources for Lifelong Learning? (Paris: OECD).

OHMAE, K. (1990) The Borderless World (London: Collins).

OHMAE, K. (1996) The End of the Nation State: The Rise of Regional Economies (London: Harper Collins).

PIETERSE, J. N. (1995) 'Globalization as Hybridization' in M. Featherstone, S. Lash and R.

Robertson (eds), Global Modernities (London: Sage), pp. 45-68.

PIORRE, M. and SABEL, C. (1984) The Second Industrial Divide (New York: Basic Books).

PUTNAM, R. (2001) Bowling Alone: The Collapse and Revival of American Community (London : Simon and Schuster).

REICH, R. (1991) The Work of Nations: A Blueprint for the Future (New York: Vintage).

REICH, R (2001) The Future of Success ( New York: Alfred A. Knopf).

RINNE, R., KIVIRAUMA, ARO, M. and SIMOLA, H. (????) North Vs South: Opinions of the Youth and the New Educational Policies of Five Post-Industrial Countries in Comparative Perspective.

ROBERTSON, R. (1995) 'Globalization: Time-Space and Homogeneity-Heterogeneity’ in M. Featherstone, S. Lash and R. Robertson (eds) Global Modernities (London: Sage), pp. 25-45.

STAHL, T., NYHAN, B. and D'ALOJA, P. (1993) The Learning Organization: A Vision for Human Resource Development (Brussels: European Commission). 
STREECK, W. (1996) 'Lean Production in the German Automobile Industry: A Test Case for Convergence Theory', in S. Berger and R. Dore (eds) National Diversity and Global Capitalism, Cornell University Press, New York, pp.138-170.

TANGUY, L. (1991) L'Enseinement Professionnel en France (Paris: PUF).

THUROW, L. (1996) The Future of Capitalism (New York: Nicholas Brearley Publishing).

WATERS, M. (1995) Globalization (London: Routledge).

Andy Green is a professor of education at the London University Institute of Education and co-director of the Department for Education and Skills - funded Wider Benefits of Learning Research Centre (WBLRC). His main field of research is the comparative study of education and training systems in which he has published widely and conducted research and consultancy for a variety of national and international bodies. His current research with the WBLRC focuses on the effects of learning on civic participation and social cohesion. 
